\title{
Evaluation of culture media for biomass production of Trichoderma viride (KBN 24) and their production economics
}

\author{
Kishor Chand Kumhar, Azariah Babu, Mitali Bordoloi, Ashif Ali \\ Tea Research Association, North Bengal Regional Research \& Development Centre, Nagrakata, District - Jalpaiguri, West Bengal - 735 225, \\ India
}

\author{
Email address: \\ kishorkumarc786@gmail.com (K. C. Kumhar)
}

\section{To cite this article:}

Kishor Chand Kumhar, Azariah Babu, Mitali Bordoloi, Ashif Ali. Evaluation of Culture Media for Biomass Production of Trichoderma viride (KBN 24) and their Production Economics. American Journal of Agriculture and Forestry. Vol. 2, No. 6, 2014 , pp. $317-320$.

doi: 10.11648/j.ajaf.20140206.24

\begin{abstract}
The Genus Trichoderma is of immense importance in agricultural crop protection because of their bio-control potential role against an array of phytopathogens through several modes of action. It is well established with fairly good acceptability, worldwide. The establishment and utilization on a commercial level of any promising isolate may not be successful, unless the cost effective mass production is evident. Present study is aimed at the evaluation of the laboratory media as well as locally available food grains for cost effective mass production of local strain KBN-24 (Trichoderma viride) for large scale adoption. Among different lab media, potato dextrose agar (solid medium) and potato dextrose broth (liquid medium) yielded comparatively more biomass of tested strain of Trichoderma viride. However, among the different grains rice ranked the first which produced the maximum biomass (148.04 gram) followed by wheat (126.87 gram) where as maize produced the least biomass. Similar trends were recorded on the conidial production and colony forming units (CFUs) in case of potato dextrose agar, potato dextrose broth and rice whole grain. Results indicated that the locally available food grains like rice and wheat were comparatively cheaper and serve as convenient substrates for the mass multiplication of Trichoderma viride and their cost economics were also discussed.
\end{abstract}

Keywords: Trichoderma Viride, Mass Multiplication, Culture Media, Production Economics

\section{Introduction}

In the current era of agriculture, the plant protection paradigm has been shifted towards integrated pest \& disease management (IPDM) approach which gained popularity and acceptance to a considerable extent among the agricultural community including researchers. Since injudicious agrochemical usage is responsible for wide range of side effects [1]. Management of plant diseases though biological control agents is ideal and need of hour. This practice (biological control) is successfully established in different crops in different agro-ecological regions. Trichoderma is one of the most common fungal bio control agents which is being widely used for the management of various foliar and soil borne plant pathogens [2]. It has been acclaimed as an effective, eco-friendly, cheaper, and reducing the ill effects of synthetic chemicals due to its unique modes of action such as competition, antibiosis and enzymatic. Different species of
Trichoderma are being used to protect tea plantation from some of the plant pathogens of economic importance [3] in many parts of India. However, its local strain from the tea ecosystem in Dooars region of West Bengal, is still needs to explored. Its successful utilization as a potential biocontrol agent at the garden level needs isolation of effective local strain, standard and cost effective mass multiplication techniques. Various substrates including grains may be used for mass multiplication of $T$. viride with variable mass productivity [4]. The success of any biological control agent not only depends on its virulence but also on the successful mass production in laboratory assuring cost effectiveness and its shelf life. Therefore looking towards need for large scale cost effective production of eco-friendly bio-pesticide, present investigation has been carried out to evaluate locally available less expensive substrates for mass multiplication of $T$. viride for sustainable tea cultivation. Solid state fermentation has an edge over submerged (liquid state) 
fermentation in terms of high volumetric productivity, low cost equipments, much lesser by-product or waste generation and lesser time [5].

\section{Materials and Methods}

Solid synthetic, liquid synthetic media were procured from Himedia and and food grains (rice, maize and wheat) from the local market (Table 1) and evaluated for their suitability for mass multiplication of $T$. viride $(\mathrm{KBN}-24)$ following the methods adopted by earlier workers with slight modifications $[6,7]$. Petri plates of $90 \mathrm{~mm}$ diameter were used for solid media whereas, for liquid media as well as food grains, 250 $\mathrm{ml}$ capacity conical flasks were used adopting CRD (Complete randomised design). Sterilized media was poured in to each Petri plate $(20 \mathrm{ml} /$ plate $)$ and allowed the same for solidification.

In the case of liquid synthetic media $250 \mathrm{ml}$ capacity conical flasks, broth media $(100 \mathrm{ml})$ along with the selected food grains $(100 \mathrm{~g})$ were taken. Food grains were soaked in distilled water for 15-20 minutes to make them soft, excess water was drained off and $2 \%$ sugar solution was added. The mouth of the flasks was closed using cotton plugs. All conical flasks were autoclaved $121{ }^{0} \mathrm{C}$ (15 psi) for $15-20$ minutes.

All plates and flasks were inoculated with $5 \mathrm{~mm}$ mycelial discs of 4-7 days old pre-cultured $T$. viride using a sterilized cork borer and incubated for 15 days at room temperature. After 15 days, biomass produced was estimated by weighing, haemocytometer observations and plating technique (Fig.1) and the cost of economics was calculated for the different media. Each treatment was replicated three times.

Table 1. Media of media for T. viride (KBN-24) mass production.

\begin{tabular}{llll}
\hline SN & Culture Media & Media state & $\begin{array}{l}\text { Quantity of media } \\
\text { used per treatment }\end{array}$ \\
\hline 1 & Potato dextrose agar & Solid & $20 \mathrm{ml} /$ Petriplate \\
2 & Sabouraud Dextrose Agar & Solid & $20 \mathrm{ml} /$ Petriplate \\
3 & Potato dextrose broth & Broth & $100 \mathrm{ml} /$ flask \\
4 & Czapek Dox Broth & Broth & $100 \mathrm{ml} /$ flask \\
5 & Rice & Grain & $100 \mathrm{gm} /$ flask \\
6 & Wheat & Grain & $100 \mathrm{gm} /$ flask \\
7 & Maize & Grain & $100 \mathrm{gm} /$ flask \\
\hline
\end{tabular}

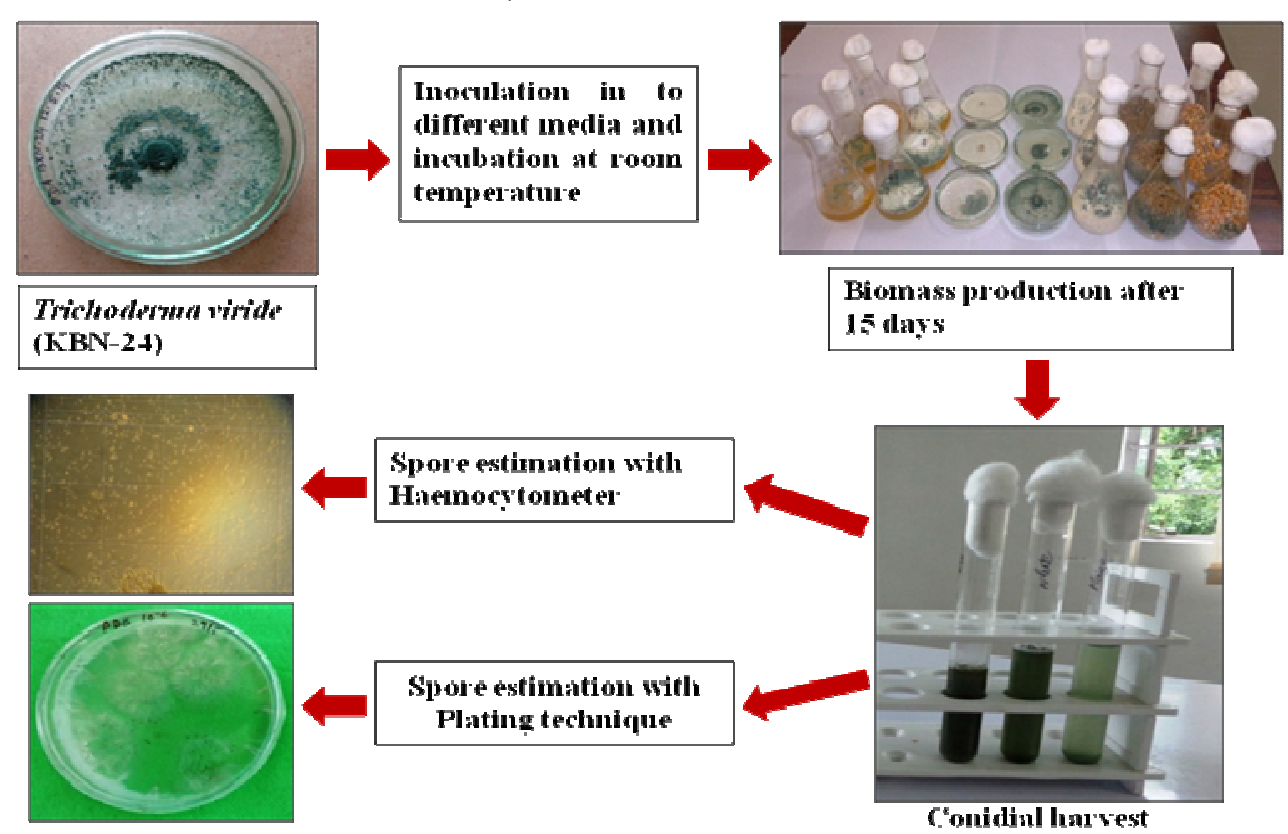

Figure 1. Experiment design to evaluate the media for blomass production of Trichoderma viride (KBN-24)

\section{Results and Discussion}

\subsection{Solid Synthetic Media}

The results of the two different laboratory media viz., potato dextrose agar (PDA) and Sabouraud dextrose agar (SDA) which were evaluated for mass multiplication are presented in (Table 2). Results indicated that, the potato dextrose agar is better than Sabouraud dextrose agar in terms of biomass produced (Fig. 2). The PDA medium produced $0.54 \mathrm{~g}$ (fresh weight) per plate whereas; the SDA medium could produce only $0.37 \mathrm{~g}$ of biomass including both fungal conidia and mycelia.
Table 2. Biomass production of T. viride (KBN-24) in different media.

\begin{tabular}{ll}
\hline Media & Fresh weight of biomass (gram)* \\
\hline Potato Dextrose Agar & $0.54 \pm 0.05$ \\
Sabouraud Dextrose Agar & $0.37 \pm 0.05$ \\
Potato Dextrose Broth & $96.30 \pm 0.36$ \\
Czepek Dox Broth & $90.38 \pm 0.16$ \\
Rice & $148.04 \pm 4.97$ \\
Wheat & $126.87 \pm 5.26$ \\
Maize & $114.79 \pm 5.68$ \\
C.D. & 10.66 \\
SE(m) & 3.48 \\
SE(d) & 4.92 \\
C.V. & 7.39 \\
\hline
\end{tabular}

*Mean of 3 replications 
Table 3. Conidial production of T. viride ( $K B N-24)$ in different media.

\begin{tabular}{|c|c|c|c|c|}
\hline Media & $\begin{array}{l}\text { Water added to harvest } \\
\text { conidial biomass }\end{array}$ & $\begin{array}{l}\text { final amount of spore } \\
\text { suspension after addition of } \\
\text { water }(\mathrm{ml})\end{array}$ & $\begin{array}{l}\text { Conidia / column of } \\
\text { Haemocytometer field (at } \\
\text { 10X)* }\end{array}$ & $\begin{array}{l}\text { Conidia / ml / } \\
\text { Haemocytometer field* }\end{array}$ \\
\hline Potato Dextrose Agar & $15 \mathrm{ml}$ & 15 & 167 & $10.00 \pm 0.67$ \\
\hline Sabouraud Dextrose Agar & $15 \mathrm{ml}$ & 15 & 46 & $3.51 \pm 0.38$ \\
\hline Potato dextrose broth & 0 & 100 & 268 & $2.44 \pm 0.14$ \\
\hline Czapek Dox Broth & 0 & 100 & 53 & $0.54 \pm 0.01$ \\
\hline Rice & $150 \mathrm{ml}$ & 150 & 131 & $3.19 \pm 0.37$ \\
\hline Wheat & $150 \mathrm{ml}$ & 150 & 240 & $1.88 \pm 0.15$ \\
\hline Maize & 150 & 150 & 419 & $0.72 \pm 0.09$ \\
\hline C.D. & & & & 1.03 \\
\hline $\mathrm{SE}(\mathrm{m})$ & & & & 0.34 \\
\hline $\mathrm{SE}(\mathrm{d})$ & & & & 0.47 \\
\hline C.V. & & & & 18.25 \\
\hline
\end{tabular}

*Mean of 3 replications

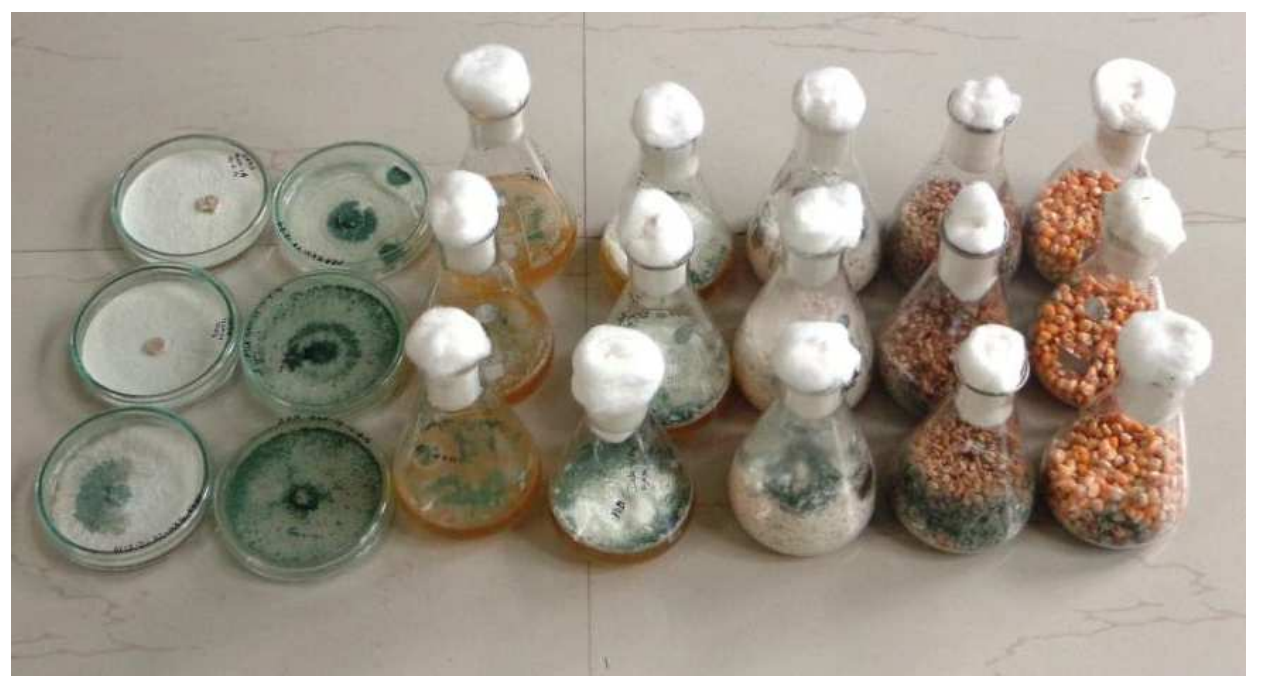

Figure 2. Mycelial growth and sporulation on different media and food grains.

\subsection{Synthetic Broth Synthetic Media}

Among synthetic broth media, potato dextrose broth (PDB) performed better than Czapek Dox broth (Table 2 and fig 2) which produced 96.30 gram as compared to second media, with 90.38 gram biomass (fresh weight).

\subsection{Food Grains}

Table 4. CFU estimation of T. viride (KBN-24) plating technique.

\begin{tabular}{lll}
\hline SN & Media & CFUs at 10 \\
\hline 1 & Potato dextrose agar & $91.89 \pm 23.42$ \\
2 & Sabouraud Dextrose Agar & $59.75 \pm 33.30$ \\
3 & Potato dextrose broth & $12.86 \pm 2.51$ \\
4 & Czapek Dox Broth & $8.54 \pm 1.66$ \\
5 & Rice & $40.62 \pm 12.32$ \\
6 & Wheat & $30.69 \pm 6.31$ \\
7 & Maize & $29.07 \pm 12.64$ \\
& C.D. & 51.99 \\
& SE(m) & 16.98 \\
& SE(d) & 24.01 \\
& C.V. & 75.28 \\
\hline
\end{tabular}

*Mean of 3 replications

In the case of the three different grains, rice ranked first with 148.04 gram biomass followed by wheat (126.87 gram) and maize (114.79 gram) according to Table 2 and Fig. 2. Conidial quantity assessment was undertaken after 15 days. Potato dextrose agar, potato dextrose broth and rice produced $91.89,12.86$ and 40.62 colony forming units, at $10^{-8}$ dilution, respectively (Table 4).

\section{Determination of Cost Economics}

The cost of different media and food grains were considered to work out the production cost. Among the solid synthetic media, potato dextrose agar was found to be cheaper than Sabouraud Dextrose Agar. In liquid media, potato dextrose broth was economic than Czapek Dox Broth (Table 5). Several plant materials such as Tripxacum laxum,Cymbopogon citrates, Crotalaria anagyroids, Albizzia chinensis, Indigofera stachyodes, Albizzia Montana and Derris robusta were evaluated by earlier workers [8] and reported that Tripxacum laxum yielded the maximum cfu of $T$. harzianum $\left(6.81 \times 10^{4}\right)$ followed by Albizzia chinensis $(4.10$ x $\left.10^{4}\right)$, where as Derris robusta produced the least cfu $(7.12 \times$ $10^{3}$ ). Potato dextrose agar (PDA) and malt extract agar (MEA) 
were studied for the mycelial growth of $T$. viride and it was noted that it could produce better mycelial growth when PDA was enriched with $2.5 \mathrm{gm}$ glucose and $1.5 \mathrm{gm}$ lactose respectively [9]. It has been reported that large scale mass production of $T$. harzianum can be achieved through liquid fermentation using inexpensive media such as molasses and brewers yeast [10]. Household waste, vegetable waste and other wastes can also be utilized for mass production of $T$. candidum [11]. Vegetable waste, fruit juice waste, sugarcane baggase and rotten wheat grains have been used for mass multiplication of $T$. viride and reported that sugarcane baggase as the best substrate that yielded high amount of mycelia, spore \& higher cfu count [12]. Similarly, in the present investigation, among food grains evaluated, both rice and wheat are found to be cost effective than maize. The production cost per gram biomass in different media and substrates ranged from 0.01 to 15.11 rupees (Table 5). Cost of synthetic media varied from 0.15 to 15.11 rupees whereas mass multiplication with the use of food grains was found to be economic and the cost of production per gram of fresh biomass ranged from 0.01 to 0.08 rupees only indicating the fact that these media could serve the purpose of cost effective manner in the commercial production of this strain.

Table 5. Production economics of different media.

\begin{tabular}{|c|c|c|c|c|c|c|c|c|}
\hline Media & Media Code & $\begin{array}{l}\text { Cost ₹/ } \\
\text { per Kg (A) }\end{array}$ & $\begin{array}{l}\text { Media quantity } \\
\text { required / litre } \\
\text { (B) }\end{array}$ & $\begin{array}{l}\text { Cost ₹ / litre } \\
\text { media } \\
(C=A / 1000 x \\
\text { B) }\end{array}$ & $\begin{array}{l}\text { Quantity of } \\
\text { media used (ml } \\
\text { or g) per } \\
\text { treatment (D) } \\
\end{array}$ & $\begin{array}{l}\text { Cost ₹/ } \\
\text { treatment } \\
(\mathrm{E}=\mathrm{C} / \mathbf{1 0 0 0} \mathrm{x} \\
\text { D) } \\
\end{array}$ & $\begin{array}{l}\text { Gram Biomass } \\
\text { produced }(\mathrm{F})\end{array}$ & $\begin{array}{l}\text { Production } \\
\text { cost ₹ / g } \\
(G=E / F)\end{array}$ \\
\hline PDA & MH096-500G & 4210 & 39 & 164.19 & 20 & 3.28 & 0.54 & 6.07 \\
\hline SDA & M063-500G & 4300 & 65 & 279.50 & 20 & 5.59 & 0.37 & 15.11 \\
\hline PDB & M403-500G & 4352 & 24 & 104.45 & 100 & 10.44 & 90.30 & 0.12 \\
\hline $\mathrm{CDB}$ & M076-500G & 3876 & 35.01 & 135.70 & 100 & 13.57 & 90.38 & 0.15 \\
\hline Wheat & - & 16 & & & 100 & 1.60 & 126.87 & 0.01 \\
\hline Maize & - & 90 & & & 100 & 9.00 & 114.79 & 0.08 \\
\hline
\end{tabular}

*Values represent mean of 3 replications

\section{Acknowledgements}

We gratefully acknowledge the help rendered by Dr. S. K. Singh, Co-ordinator, Agharkar Research Institute, Pune, India in identifying the strain. The authors are also thankful to Dr. N. Muraleedharan, Director, TRA Tocklai Tea Research Institute, Jorhat, Assam, for his constant support, guidance and encouragement.

\section{References}

[1] S. Roy, A. Mukhopadhyay and G. Gurusubramanian. (2011) Resistance to insecticides in field collected population of tea mosquito bug (Helopeltis theivora Waterhouse) from the Dooars (North Bengal, India) tea cultivations. J. Entomol. Res. Soc., 13(2): 37-44.

[2] F.C. Dominguesa, J.A. Queiroza, J. M. S. Cabralb and L. P. Fonsecab. (2000) The influence of culture conditions on mycelial structure and cellulose production by Trichoderma reesei rut C-30. Enz. Microbial Technol. 26: 394-401.

[3] B. K. Borthakur and P. Dutta. (2011) Disease management in tea, In Tea field management, Tea Research Association, Tocklai Experimental Station, Jorhat -785 008, Assam, India, pp. 182-188.

[4] E. Esposito and M. da Silva. (1998) Systematics and environmental application of the genus Trichoderma. Crit. Rev. Microbiol. 24:89-98.

[5] G.S. Kocher, K.L. Kalra, G. and Banta. (2008) Optimization of cellulase production by submerged fermentation of rice straw by Trichoderma harzianum Rut-C 8230. Int. J. Microbiol. 5(2): 8230 .
[6] N. Subash, J. Viji, C. Sasikumar, and M. Meenakshisundaram. (2013) Isolation, media optimization and formulation of Trichoderma harzianum in agricultural soil. Journal of Microbiology and Biotechnology Research.3 (1): 61-64.

[7] Mridula Khandelwal, Sakshi Datta, Jitendra Mehta, Ritu Naruka, Komal Makhijani, Gajendra Sharma, Rajesh Kumar and Subhas Chandra. (2012) Isolation, characterization \& biomass production of Trichoderma viride using various agro products- A biocontrol agent. Advances in Applied Science Research, 2012, 3 (6):3950-3955.

[8] D. Ajay, J. S. Bisen, M. Singh, R. Saha and B. Bera. (2013) Evaluation of various plant residues in tea plantations of Darjeeling for on farm production of Trichoderma harzianum. Indian Journal of research and practices. 1: 1-4.

[9] Prashant Pingolia, Rohini Maheshwari, Narendra Vaishnav, Gajendra P. Sharma and Jitendra Mehta. (2013) Mycelium growth of Trichoderma viride (Biocontrol agent) on different agar medium. International Journal of Recent Biotechnology. $1(1): 43-47$.

[10] G. C. Papavizas, M. T. Dunn, J. A. Lewis and J. BeagleRistaino. (1984) Liquid fermentation technology for experimental production of biocontrol fungi. Phytopathology. 74:1171-1175.

[11] K. Nagur Babu, and P.N. Pallavi. (2013) Isolation, identification and mass multiplication of Trichoderma an important bio-control agent. International Journal of pharmacy and life sciences. 4(1): 2320-2323.

[12] P. J. Chaudhari, Prashant Shrivastava and A. C. Khadse. (2011) Substrate evaluation for mass cultivation of Trichoderma viride. Asiatic Journal of Biotechnology Resources. 2(04): 441-446. 